\title{
Analysis of Skid Resistance and Noise Characteristics for Varieties of Concrete Pavement
}

\author{
Jinmiao Fang, Jinsong Tu $(\mathbb{D}$, and Kunming $W u$ \\ School of Architecture and Civil Engineering, West Anhui University, Lu'an 237012, China \\ Correspondence should be addressed to Jinsong Tu; 05000065@wxc.edu.cn
}

Received 23 February 2020; Accepted 26 May 2020; Published 30 June 2020

Academic Editor: Luís Evangelista

Copyright (C) 2020 Jinmiao Fang et al. This is an open access article distributed under the Creative Commons Attribution License, which permits unrestricted use, distribution, and reproduction in any medium, provided the original work is properly cited.

To establish evaluation criteria for the pavement skid resistance and noise level in tunnels pavements, the zoning and control standards for skid resistance and concrete pavement noise were examined. Transverse friction coefficient (TFC) test equipment and the on-board sound intensity (OBSI) method were used to evaluate the antisliding characteristics and noise levels of several tunnel pavements. The results indicated poor antisliding characteristics and noise levels in ordinary grooved cement concrete pavement, whereas new types of cement concrete pavements, such as exposed concrete pavements and polymer-modified cement concrete pavements, had good antisliding characteristics and achieved low noise levels. Combined with the cluster analysis method, a zoning method for the antisliding and noise level in concrete pavement is proposed. The antisliding characteristics and noise levels of the pavement are divided into three zones. To ensure safety and comfort during driving, the antisliding value (SFC) of the tunnel pavement should be more than 50, and the noise level should not exceed $105 \mathrm{~dB}$. Finally, the correlation between the antisliding and noise levels for pavement was analyzed. The results indicated that the antiskiding value of pavement has a strong correlation to the noise level.

\section{Introduction}

In recent years, concrete pavement has been encouraged to replace the asphalt pavements because of their advantages, such as easy maintenance, long service life, and durability [1]. The concrete pavement is completely nonflammable and nontoxic in the case of a fire accident in tunnels [2]. Additionally, compared to asphalt pavement, it can reduce the electrical energy consumption because of its light surface [3].

However, because of the unique climatic environment within tunnels and the material characteristics of the cement concrete pavement, the concrete pavement of the tunnels has many shortcomings. The most problematic of which are the skid resistance and noise [4-6]. Domestic research on tunnel engineering mainly focuses on the structural design and construction technology. Previous research on the concrete pavement used in tunnels mainly focuses on the skid resistance, and relatively little attention has been paid to noise reduction for ensuring driving comfort [7].
Conventional methods for highway cement concrete pavement design and construction are being applied to concrete pavements used in tunnels. Because of the unique environment inside tunnels, the pavement performance requirements differ significantly from those of ordinary cement concrete. This leads to a different degree of disease in tunnel cement concrete pavement [8]. One of the most significant problems results from the susceptibility of cement concrete pavement to pollution and the susceptibility of the surface texture to wear. The pollutants such as vehicle oil pollution and tire scraps spilled on the road surface, which can reduce the skid resistance of the concrete pavement. The antisliding performance of the pavement attenuates quickly [9]. The skid resistance of pavements decreases by $8-12 \%$ owing to the filling of pavement porosity [10]. This reinforces traffic security dangers. Additionally, owing to the long-term wet condition of the tunnel pavement surface [11], particularly during the low-temperature winter period, the concrete pavement is more likely to freeze, which significantly affects its skid resistance [12]. 
Temperature variations can influence significantly the skidresistance values [13].

Furthermore, owing to the closed environment of the tunnel, it is difficult to dissipate noise during driving, significantly affects driving comfort [14]. Tire-pavement noise is one of the main sources of vehicle noise. Road surface noise is emitted and is superimposed in the tunnel, making it last longer and making it more difficult to be dissipated, which reduces the driving comfort. The tire-pavement noise is generally higher than $90 \mathrm{~dB}$ in the long highway tunnels [15]. Zhang found that the tire-pavement noise inside the tunnel is $20 \mathrm{~dB}$ (A) higher than that of external pavement [16]. There is poor correlation between skid-resistance values and tire-pavement noise, regardless of groove textures [16]. The tire-pavement noise is a key problem to be solved in tunnel driving $[15,17]$.

In summary, the unique environment of the tunnel rapidly attenuates the skid resistance of pavement. It also amplifies road-traffic noise and negatively influences the safety and comfort of tunnel driving. Therefore, research on skid resistance and noise control for tunnel pavements is imperative needed [17]. In this study, via the comprehensive testing of different road types and surface textures, skid resistance and noise classification standards for tunnel concrete pavement were proposed. The control standards for skid resistance and noise security ensure that vehicles operate "safely" and "quietly" in tunnels. For the sections below the limits for the sliding resistance and low noise, pavement maintenance must be promptly conducted to ensure the safety of vehicle travel.

\section{Experiment and Method}

2.1. Road Information. To test the antisliding force coefficient and noise level of the concrete pavement for several expressways in China, data were collected for traditional grooved cement concrete pavement and new types of cement concrete pavements (polymer-modified cement concrete pavement (PCC) and exposed concrete pavement (EACCP)). The main pavement texture types are shown in Figure 1. To ensure the diversity of the antiskid grading data samples, this study also selected asphalt pavements, namely, dense asphalt concrete (AC) and stone matrix asphalt (SMA), which were used as comparison samples to comprehensively test the antiskid value and noise level of different types of pavement textures. Details regarding the concrete pavement testing are presented in Table 1.

\subsection{Test Methods}

2.2.1. Pavement Surface Friction Coefficient. The pavement friction coefficient detection system (as shown in Figure 2) was mainly used to determine the transverse friction coefficient (SFC) of the concrete pavement, to assess its skid resistance. The measurement system included the following instruments and equipment, all of which utilized numerical control: a test trailer, sprinkler equipment, an electric control box, and supporting computer software. The test speed was $60 \mathrm{~km} / \mathrm{h}$. The sampling frequency was $1 \mathrm{~m}$. Under these conditions, the SFC of the road surface was accurately measured; thus, the skid resistance of the road surface was assessed.

The SFC has become an important index for the evaluation of the antiskid force during the completion and acceptance of highways in China. Regulations stipulate that the SFC for general sections of highways should not be less than 0.50 , while it should not be less than 0.55 in special sections [18].

2.2.2. Road/Tire Noise Test. The pavement noise was evaluated using the on-board sound intensity (OBSI) method, where digital signal acquisition was employed to measure the noise signal on the unit area of the space point near the tire/road interface at a constant speed over a period of time. The road noise sound pressure level and octave spectrum were analyzed and obtained $[14,19,20]$. The A-weighted sound level was used because A-weighting is a valid indicator of the perceived loudness or annoyance of road-traffic sound [21]. A standard test tire (ASTM E 1136) was used to evaluate the road noise. The vehicle speed in the test was $60 \mathrm{~km} / \mathrm{h}$. The frequency of tire/road noise data acquisition was $10000 \mathrm{~Hz}$, as shown in Figure 3.

2.3. Cluster Analysis Method for Evaluation. A multivariate statistical clustering analysis was performed to extract the primary features of the sample data and establish clustering indices among different data, to define the classification standards for antiskid and noise levels of different tunnel pavements. The cluster analysis method is a multivariate statistical analysis method in which research objects are classified according to the characteristics of different types of samples and the "affinity" of the sample data. Clusters are determined via the clustering analysis method, according to the similarity of the internal data features. There is a large difference between different clusters, to accurately distinguish the characteristic relationship between different data groups [22]. The main calculation process is shown in Figure 4 [23].

\section{Results and Discussion}

\subsection{Pavement Antiskid Characteristics and Zoning}

3.1.1. Antiskid Characteristics of Pavement. The statistical results for the slip resistance values of different tunnel pavements are presented in Figure 5. Table 2 shows the statistical results of SFC.

As can be seen from Figure 5 and Table 2, we can get the following:

(1) The sliding resistance of the asphalt surface was significantly higher than that of ordinary cement concrete pavement. When the cement concrete road surface in the form was used, such as EACCP and PCC, the skid resistance of the cement concrete pavement was significantly improved. With regard to the sliding resistance of EACCP, the skid-resistance value is larger than 65 , and the coefficient of variation 


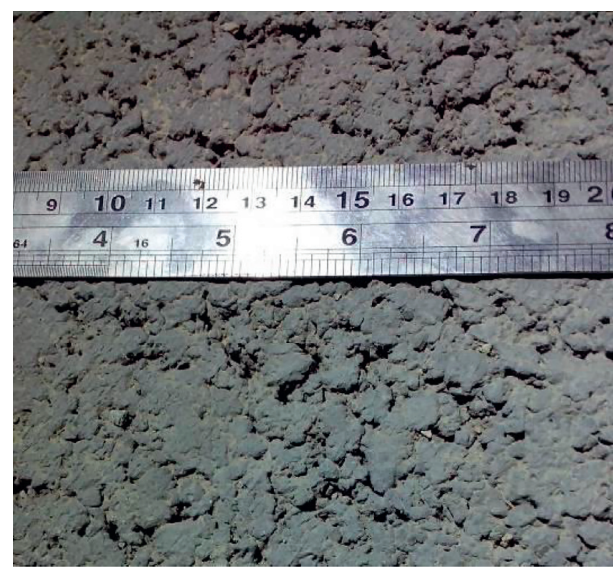

(a)

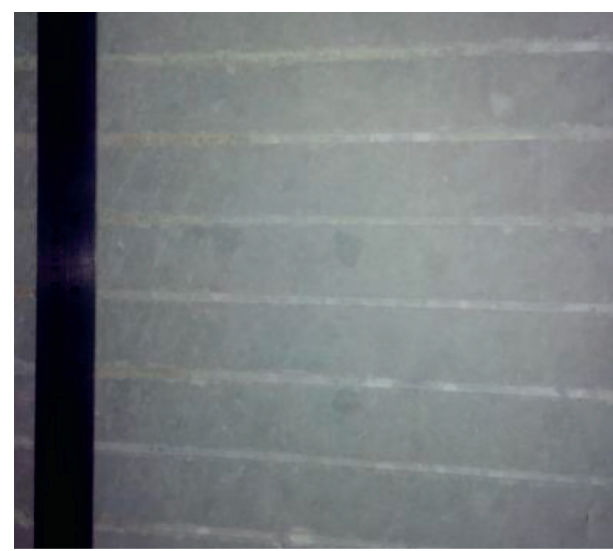

(c)

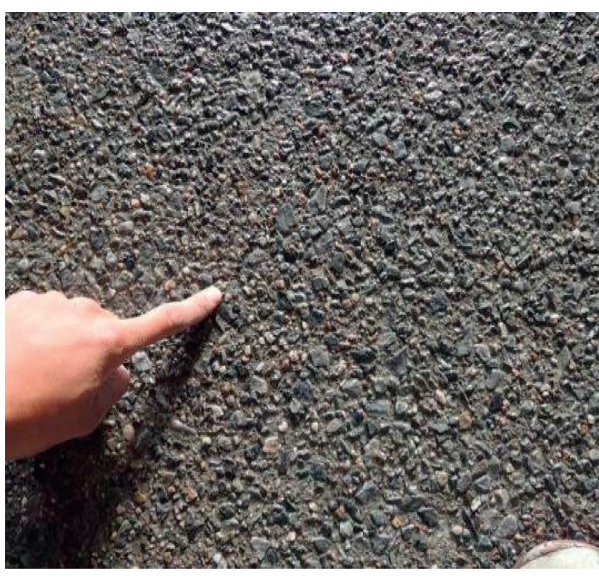

(b)

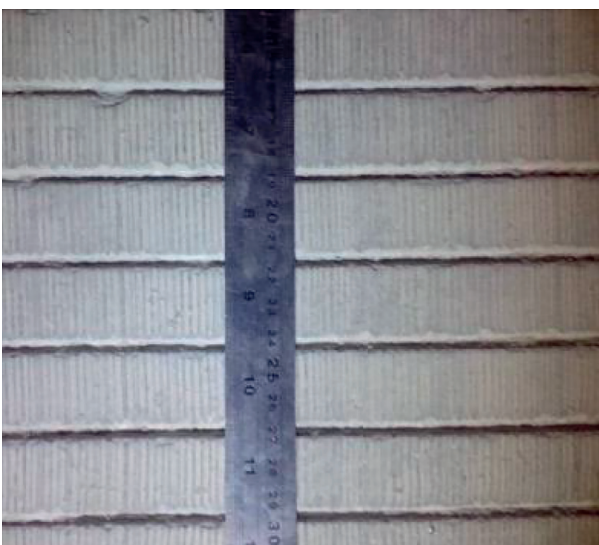

(d)

Figure 1: Typical pavement texture types. (a) PCC. (b) EACCP. (c) Groove (no drag). (d) Groove (artificial turf drag).

TABLE 1: Details of testing concrete pavement.

\begin{tabular}{|c|c|c|c|c|}
\hline No. & Pavement type & Spacing, width, and depth of groove (mm) & Test location & Traffic condition \\
\hline $\mathrm{A}$ & Trancyerce oroove (artificial turf drag) & $20,5,5$ & Tunnel 1 & \multirow{3}{*}{ Newly built } \\
\hline B & mansverse groove (artincial turn arag) & $50,5,5$ & 1 unner 1 & \\
\hline $\mathrm{C}$ & Transverse groove (no drag) & $25,5,5$ & Tunnel 2 & \\
\hline $\mathrm{D}$ & \multirow{2}{*}{ Longitudinal grooving } & $25,5,5$ & Tunnel 1 & \multirow{2}{*}{5 years } \\
\hline $\mathrm{E}$ & & $25,5,2 \sim 4$ & Tunnel 3 & \\
\hline $\mathrm{F}$ & Transverse groove & $25 / 50,5,5$ & Tunnel 1 & Newly built \\
\hline G & \multirow{2}{*}{ Longitudinal grooving } & Random & Tunnel 1 & \multirow{2}{*}{3 years } \\
\hline $\mathrm{H}$ & & Random & Tunnel 4 & \\
\hline I & Transverse groove & $23,5,1 \sim 3$ & Tunnel 5 & 2 years \\
\hline $\mathrm{J}$ & EACCP & - & Tunnel 6 & Newly built \\
\hline K & PCC & - & Tunnel 4 & Newly built \\
\hline $\mathrm{L}$ & SMA & SMA-13 & Tunnel 7 & Newly built \\
\hline M & HMA & AC-13 & Highway pavement & Newly built \\
\hline $\mathrm{N}$ & Transverse groove (no drag) & $25,5,1-3$ & Tunnel 8 & Newly built \\
\hline $\mathrm{O}$ & Bridge deck pavement & AC-13 & A large bridge & Newly built \\
\hline
\end{tabular}

was small. When a bridge deck is made of ordinary asphalt concrete, the antisliding force of the bridge deck is weaker than that of the ordinary road section because of its higher stiffness.

(2) The antislip force of the newly laid cement concrete pavement was relatively strong and was significantly affected by the microtexture of the cement concrete. When the road surface was treated with drag, its antiskid value become significantly higher than that of the smooth cement concrete pavement. Its antislip value increased by up to $50 \%$.

(3) Common grooved cement concrete pavement had poor skid resistance. 


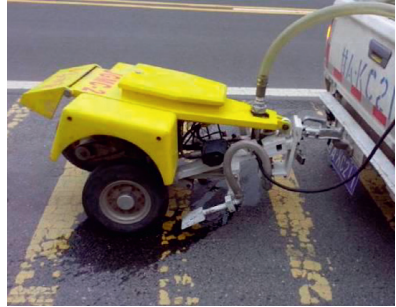

(a)

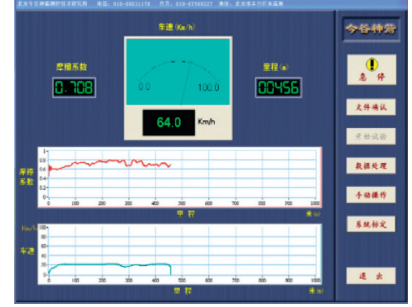

(b)

Figure 2: The pavement surface friction coefficient test equipment: (a) test trailer and (b) data acquisition system.

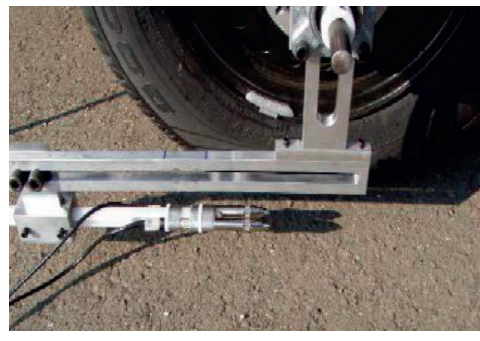

(a)

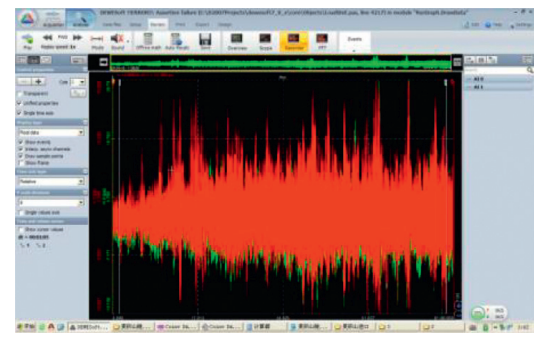

(b)

FIGURE 3: On-board sound intensity (OBSI) method: (a) noise testing system and (b) data acquisition system.

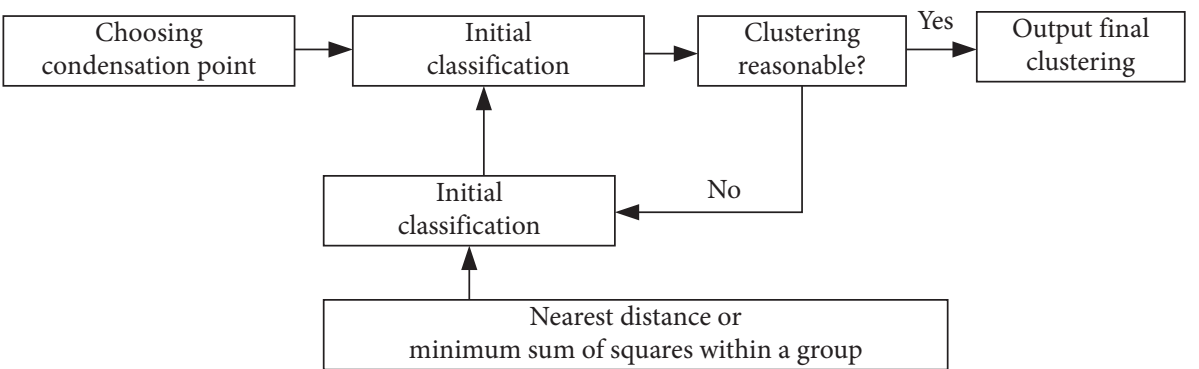

Figure 4: Dynamic clustering computing process [23].

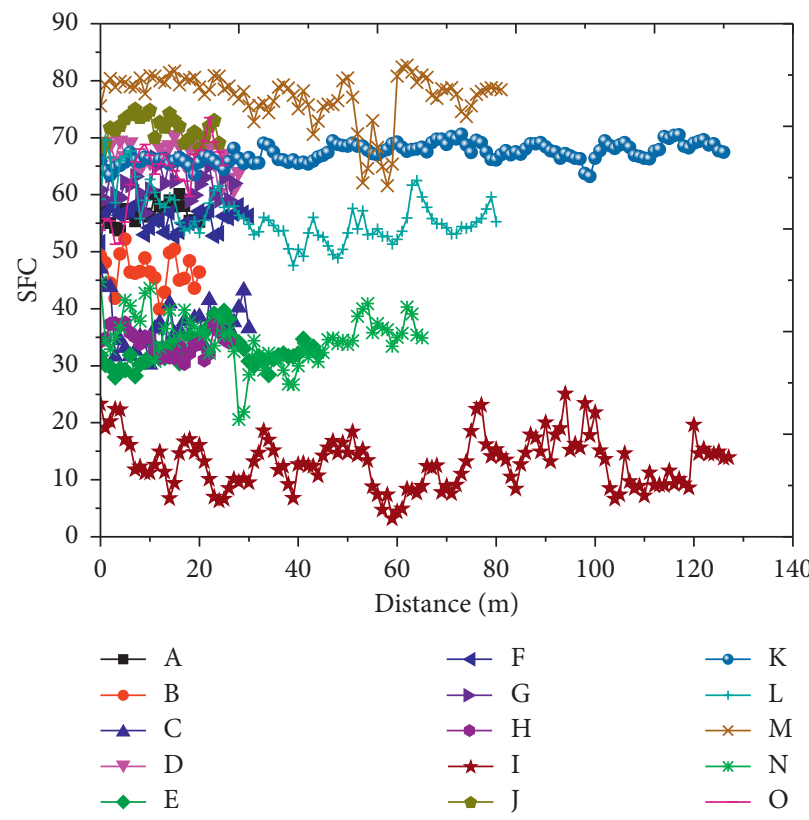

Figure 5: Test results of different pavement skid resistance. 
TABLE 2: Statistical results of pavement skid resistance.

\begin{tabular}{|c|c|c|c|c|c|}
\hline No. & Pavement type & $\mathrm{SFC}_{\min }$ & $\mathrm{SFC}_{\max }$ & $\mathrm{SFC}_{\mathrm{ave}}$ & $\overline{\text { SFC }_{\text {variance }}}$ \\
\hline A & Transverse groove (artificial turf drag) & 53.7 & 60.1 & 56.7 & 1.7417 \\
\hline B & Transverse groove (artificial turf drag) & 39.9 & 52.2 & 46.5 & 3.1118 \\
\hline $\mathrm{C}$ & Transverse groove (no drag)) & 30.2 & 47.0 & 37.0 & 4.0939 \\
\hline $\mathrm{D}$ & Longitudinal groove & 64.6 & 70.5 & 67.5 & 1.8506 \\
\hline $\mathrm{E}$ & Longitudinal groove & 28.0 & 39.6 & 32.6 & 2.8036 \\
\hline $\mathrm{F}$ & Transverse groove & 51.6 & 58.6 & 55.7 & 1.9220 \\
\hline G & Transverse groove & 56.8 & 66.5 & 62.1 & 2.8490 \\
\hline $\mathrm{H}$ & Longitudinal groove & 30.4 & 37.5 & 34.1 & 2.2065 \\
\hline I & Transverse groove & 16.2 & 38.1 & 25.9 & 4.3963 \\
\hline $\mathrm{J}$ & EACCP & 67.2 & 75.0 & 72.1 & 2.4381 \\
\hline K & PCC & 63.2 & 70.6 & 67.3 & 1.6146 \\
\hline $\mathrm{L}$ & SMA & 47.6 & 69.6 & 56.1 & 4.4005 \\
\hline M & HMA & 70.6 & 81.0 & 76.8 & 2.2827 \\
\hline $\mathrm{N}$ & Transverse groove (no drag) & 20.6 & 44.7 & 34.7 & 4.5327 \\
\hline $\mathrm{O}$ & Bridge deck pavement & 51.3 & 73.5 & 63.2 & 6.1121 \\
\hline
\end{tabular}

Note. $\mathrm{SFC}_{\min }$ means the minimum value of $\mathrm{SFC}, \mathrm{SFC}_{\max }$ means the maximum value of $\mathrm{SFC}, \mathrm{SFC}_{\text {ave }}$ means the average value of $\mathrm{SFC}$, and $\mathrm{SFC}$ variance means the variance of SFC.

Under the existing technical conditions, the endurance of the antiskid structure in cement concrete pavement is poor, and the antiskid value of most pavements declines rapidly within a very short period of traffic. Two years after the start of use to traffic of ordinary cement concrete pavement, the antisliding force can be reduced by $50 \%$ or more, particularly for cement concrete pavement used in tunnels. In a humid environment, the concrete macrostructure is quickly ground flat, the macrostructure is rapidly attenuated, and the lateral force coefficient variation is large, which significantly affects the safety and comfort of driving.

3.1.2. Pavement Antiskid Zone. The K-means clustering analysis method was employed, and the minimum, maximum, mean, and variance of the SFCs were used as the independent variables to obtain the final K-means clustering results for the SFCs of the concrete pavement, as shown in Table 3. As can be seen from Table 3, the aggregated SFC sample data were divided into three categories: $\mathrm{SFC}<50$, $50 \leq \mathrm{SFC}<65$, and $\mathrm{SFC} \geq 65$. The classified statistical results for different road surface types are presented in Figure 6.

As can be seen from Figure 6, types D, J, K, and M represent the newly laid longitudinal grooved cement concrete pavement, EACCP, PCC, and asphalt pavement. They are classified as zone 1, with the best slip resistance. The skid resistance of zone 2 was lower than that of typical pavement types, and this zone included varieties such as newly paved transverse grooves, combined vertical and horizontal grooves, and bridge deck pavement. Zone 3 had the worst skid resistance and included varieties such as nogalling cement concrete pavement and typical cement concrete pavement after several years of operation. For the road sections corresponding to zones 1 and 2, it is safe to drive, whereas for the road section corresponding to zone 3 , the skid resistance is insufficient and presents a potential safety hazard. Therefore, to ensure safe driving, timely maintenance should be performed to improve the skid resistance to zone 1 or 2 values, to ensure safe driving.
TABLE 3: K-means clustering center of SFC of concrete pavement.

\begin{tabular}{lccc}
\hline Variation (SFC) & \multicolumn{3}{c}{ Cluster } \\
& 1 & 2 & 3 \\
\hline Minimum & 66.4 & 50.2 & 25.1 \\
Maximum & 74.3 & 65.4 & 41.4 \\
Mean & 70.9 & 56.7 & 32.9 \\
\hline
\end{tabular}

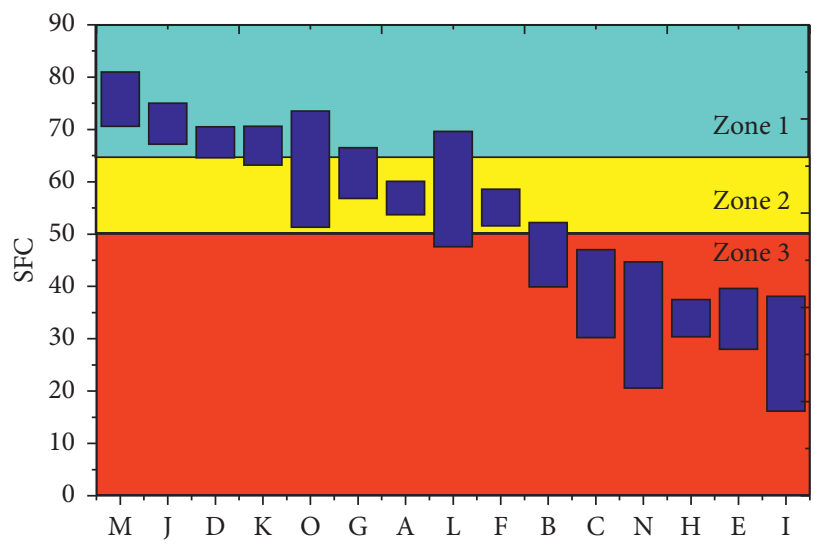

FIgURE 6: Results of the antiskid zone of concrete pavement.

\subsection{Noise Characteristics}

3.2.1. Sound Intensity (SI). The noise test results for different cement concrete pavements are presented in Table 4.

As shown in Table 4, the noise level of grooved pavement was high, and after traffic, the noise level of grooved road surfaces increased significantly. Because of the coarse aggregate exposed outside, there were rich texture structures on the surface of EACCP, which can significantly reduce noise levels [24]. The noise reduction principle was similar to that of asphalt pavement. Circulation channels were formed to compress air. Therefore, the EACCP had a noise-reduction effect. The sound pressure level was maintained at 
TABle 4: Noise of pavement test results.

\begin{tabular}{|c|c|c|c|c|c|}
\hline No. & Type of pavement & $\mathrm{SI}_{\min }(\mathrm{dB})$ & $\mathrm{SI}_{\max }(\mathrm{dB})$ & $\mathrm{SI}_{\text {ave }}(\mathrm{dB})$ & $\mathrm{SI}_{\text {variance }}$ \\
\hline A & Transverse groove (artificial turf drag) & 103.36 & 108.11 & 105.81 & 1.73 \\
\hline B & Transverse groove (artificial turf drag) & 105.63 & 110.01 & 107.82 & 1.89 \\
\hline $\mathrm{C}$ & Transverse groove (no drag)) & 106.63 & 111.92 & 109.61 & 2.88 \\
\hline $\mathrm{D}$ & Longitudinal groove & 99.26 & 105.62 & 102.16 & 2.87 \\
\hline $\mathrm{E}$ & Longitudinal groove & 107.87 & 112.05 & 110.15 & 3.57 \\
\hline F & Transverse groove & 105.45 & 109.97 & 107.92 & 1.7 \\
\hline G & Transverse groove & 102.78 & 107.57 & 105.29 & 2.83 \\
\hline $\mathrm{H}$ & Longitudinal groove & 106.83 & 112.57 & 109.58 & 3.17 \\
\hline I & Transverse groove & 108.9 & 113.82 & 111.23 & 2.97 \\
\hline $\mathrm{J}$ & EACCP & 93.27 & 99.8 & 97.67 & 0.81 \\
\hline K & PCC & 94.22 & 97.9 & 96.09 & 0.79 \\
\hline $\mathrm{L}$ & SMA & 94.47 & 96.55 & 95.44 & 0.45 \\
\hline M & HMA & 95.14 & 100.68 & 99.13 & 0.67 \\
\hline $\mathrm{N}$ & Transverse groove (no drag) & 105.72 & 111.02 & 108.43 & 1.86 \\
\hline $\mathrm{O}$ & Bridge deck pavement & 97.63 & 102.15 & 100.31 & 0.89 \\
\hline
\end{tabular}

approximately $97.0 \mathrm{~dB}$, which was $5 \mathrm{~dB}$ higher than the noise level of traditional grooving cement concrete pavement. Because of the unique road surface texture, the polymermodified cement concrete pavement can significantly reduce the noise level of cement concrete pavement. Compared with the ordinary grooving cement concrete pavement, the noise level of PCC was $6 \mathrm{~dB}$ lower. The sound pressure level was similar to that of EACCP, which was nearly $96 \mathrm{~dB}$. The microstructure of the concrete surface significantly affected the noise reduction of the cement concrete pavement. Thus, for reducing noise, ordinary cement concrete pavement should be treated with galling to form rich microstructures.

3.2.2. Road Noise Octave. The noise octave of different concrete pavements is presented in Figure 7.

As shown, for all the tested roads, the center frequency of $1 / 3$ of the octave of the road noise was a continuous octave, and the noise octave was mainly between 500 and $5000 \mathrm{~Hz}$. The noise for the different types of concrete pavement exhibited similar frequency trends. At the beginning, the noise frequencies increased. With the increase of noise frequency, the sound pressure level also gradually increased. After reaching the maximum value, it gradually decreased with a further increase in the frequency. The frequency corresponding to the highest noise level of the road was commonly in the range of $800-1600 \mathrm{~Hz}$.

Classification noise and pavement frequency range tests revealed that louder pavement noise corresponded to a higher noise frequency range curve, and when the frequency was $1000 \mathrm{~Hz}$, the sound pressure level suddenly increased. This phenomenon led to sharp noise and worsened the texture, and it occurred in transverse grooved concrete pavement or grooved surfaces after a long time. The noise octaves for pavements such as EACCP, asphalt pavement, and PCC were lower than those of other pavement types, indicating that these pavements have low noise and provide adequate comfort. Therefore, in the design and construction of concrete pavement, it is necessary to avoid selecting poor surface texture, to reduce the road noise and avoid sharp road noise.

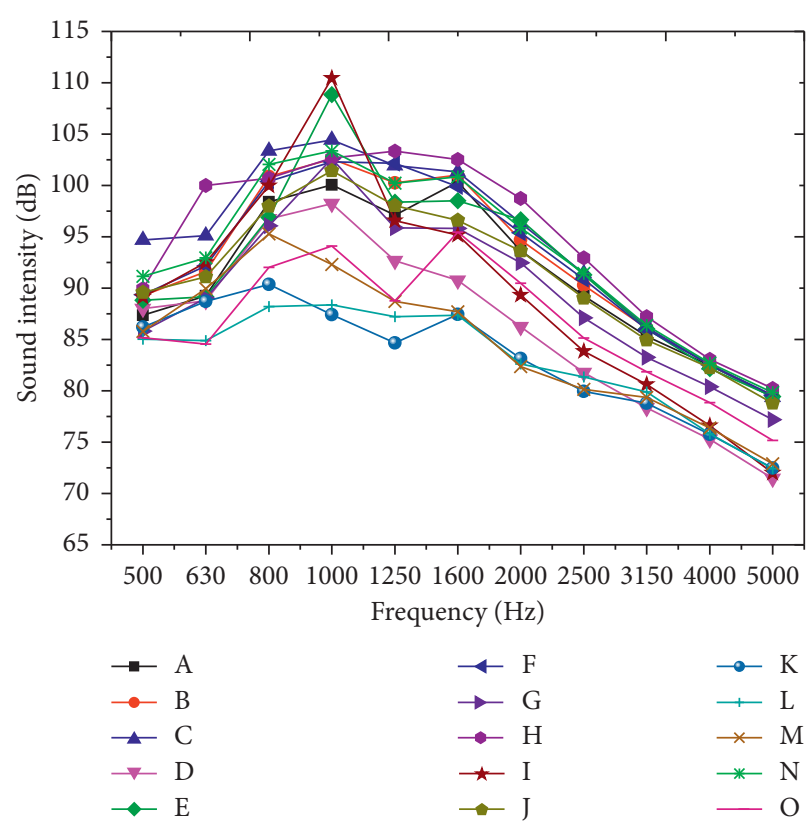

Figure 7: Comparison of the $1 / 3$ octave of different pavement textures.

3.2.3. Road Noise Zoning. According to the clustering analysis, the minimum value, maximum value, average value, and variance of antipavement noise were selected as the independent variables to obtain the final clustering results for concrete pavement noise, as shown in Table 5.

As indicated in Table 5, the same concrete pavement noise can be divided into three categories: $\mathrm{SI}<100$, $100 \leq \mathrm{SI}<105$, and SFC $\geq 105$. The classified statistical results for different road surface types are shown in Figure 8.

As can be seen from Figure 8, according to the clustering results of the noise level for different concrete pavement types, the noise test samples can be divided into 3 zones. Among them, zone 1 had the lowest noise value. Basically, all asphalt pavements, EACCP, and PCC belonged to this zone. The noise level for this type of pavement was low and the driving comfort was acceptable. The average condensation 
TABLE 5: Clustering analysis results of the noise level of concrete pavement.

\begin{tabular}{lccc}
\hline Variation (SI) & \multicolumn{3}{c}{ Cluster } \\
\hline Average & 1 & 2 & 3 \\
Variance & 97.73 & 102.81 & 108.61 \\
Maximum & 0.70 & 0.85 & 0.97 \\
Minimum & 95.15 & 100.41 & 106.03 \\
\hline
\end{tabular}

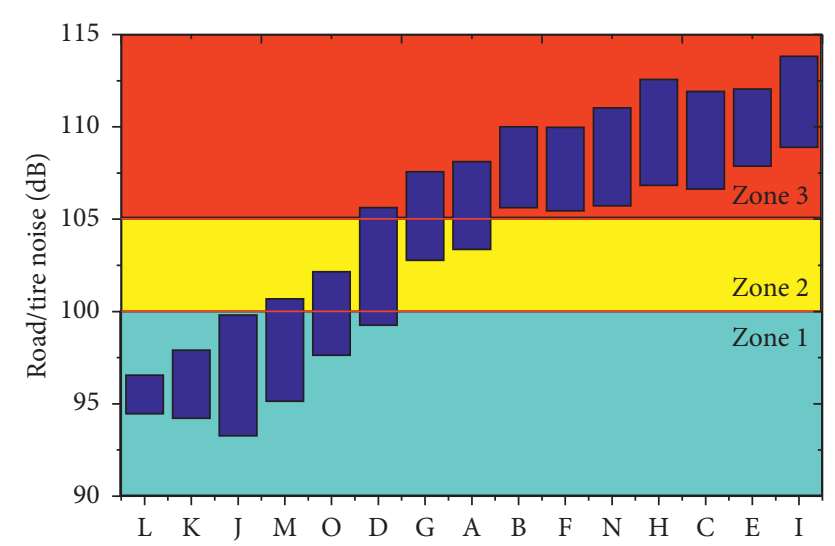

Figure 8: Concrete pavement noise zoning results.

center of noise for the concrete pavement in zone 2 was $102.8 \mathrm{~dB}$, and the maximum and minimum condensation centers were $105.71 \mathrm{~dB}$ and $100.41 \mathrm{~dB}$, respectively. The traditional grooved cement concrete pavement belonged to this zone. The average condensed center of the noise in zone 3 was $108.61 \mathrm{~dB}$, and the maximum and minimum condensed center values were $111.72 \mathrm{~dB}$ and $106.03 \mathrm{~dB}$, respectively. The opening groove of the concrete pavement, the noise level of the concrete pavement with poor grooves, and the grooved road surface after opening to traffic were similar. These types of concrete pavements exhibit a high noise level, and the road driving comfort is poor; thus, they should be avoided in the design and construction process.

To satisfy the overall needs of paved road surfaces, the boundary line of area 2 should be adopted and enforced in design and construction. Thus, the noise level should not be lower than the maximum value, which makes the noise level of the concrete pavement the overall control in zones 2 and 1 , and noise levels close to the area 3 limit should be avoided. This is due to poor road traffic, which is relatively rough and uncomfortable. Additionally, the texture of this type of pavement is poor, and the noise level is high.

\subsection{Correlation between Pavement Noise and Antiskid Force.}

The correlation between the noise levels of different road surfaces and the antiskid force was analyzed, and the results are shown in Figure 9. The sliding resistance of the road exhibited a correlation with the noise level, and the correlation coefficient was 0.7889 . A higher sliding resistance of the pavement corresponded to lower noise. This is mainly because the pavement with sufficient sliding resistance has

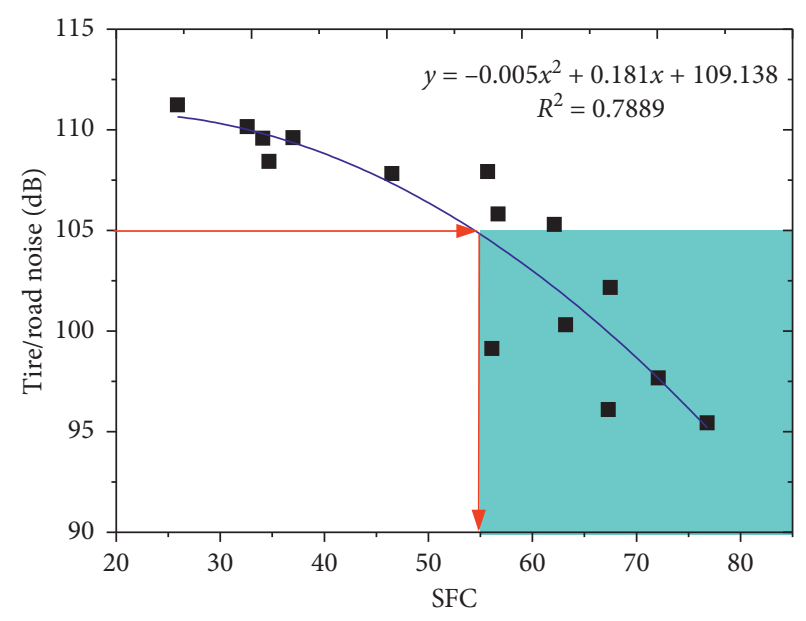

FIGURE 9: The analysis of correlation between pavement noise and antiskid force.

an adequately textured structure, which provides circulation channels for compressed air during vehicle traffic, reducing the road/tire noise. However, the sample size surveyed in this study was small. A large amount of sample data should be investigated in future study.

\section{Conclusion}

SFC testing equipment and the OBSI method were employed to evaluate the antisliding force and noise characteristics of multiple tunnel pavements. Using the clustering analysis method, zoning standards for antisliding and noise reduction of pavements were determined. The main conclusions are as follows.

Traditional grooved cement concrete pavement had poor skid resistance. The initial skid-resistance level was high, but the skid-resistance level decreased rapidly soon after exposure to traffic. In comparison, new types of cement concrete, such as EACCP and PCC, exhibited higher skid resistance. Similar results were obtained in pavement noise tests. The traditional grooved pavement was noisy and produced sharp noise, whereas the EACCP and PCC significantly reduced the noise between the pavement and tires. The cluster analysis method was adopted to divide the skid resistance and noise of the road surface into three areas. To ensure the safety and comfort of driving, it is proposed that the skid-resistance SFC of the tunnel road surface should not be $<50$ and the noise should not exceed $105 \mathrm{~dB}$. Additionally, there is a correlation between the skid resistance and the noise.

However, this study was an exploratory investigation of the zoning standard for the skid resistance and the noise level of tunnel concrete pavement. The sample size surveyed was small. To improve the reliability of the zoning standard for the skid resistance and noise of pavement concrete, additional types of tunnel pavement concrete should be investigated in future studies, for increasing the sample size.

\section{Data Availability}

The data in the manuscript are available to the readers. 


\section{Conflicts of Interest}

The authors declare no conflicts of interest.

\section{Acknowledgments}

This study was financially supported by the Key Project of Anhui Provincial Natural Science Colleges (no. 0041116025), Provincial Top-Quality Open Course Project by Anhui Provincial Department of Education (2017kfk077), and Key Project of Anhui Provincial Natural Science Colleges (KJ2019A0620).

\section{References}

[1] M. Laura, "Technical and economic sustainability of concrete pavements," Modern Applied Science, vol. 8, no. 3, pp. 1-9, 2014.

[2] E. Puente, D. Lázaro, and D. Alvear, "Study of tunnel pavements behaviour in fire by using coupled cone calorimeter - FTIR analysis," Fire Safety Journal, vol. 81, pp. 1-7, 2016.

[3] G. Cantisani, P. Di Mascio, and L. Moretti, "Comparative life cycle assessment of lighting systems and road pavements in an Italian twin-tube road tunnel," Sustainability, vol. 10, no. 11, p. $4165,2018$.

[4] P. R. Donavan, "Comparative measurements of tire/pavement noise in Europe and the United States," Noise News International, vol. 13, no. 2, pp. 2471-2488, 2005.

[5] J. G. Yang, Y. L. Xie, and Z. Xiao, "Reliability analysis on pavement skid-resistant performance in expressway tunnels," in Ninth International Conference of Chinese Transportation Professionals (ICCTP), vol. 31, pp. 145-149, Journal of Southwest University, Harbin, China, August 2009.

[6] J. P. Zhang, G. Q. Liu, and P. Z. Wang, "Skid-resistance and noise-reducing characteristics of exposed-aggregate cement concrete pavement," Advanced Materials Research, vol. 1052, pp. 352-357, 2014.

[7] D. An, J. Lee, B. Ohm, H. Son, and S. Kwon, "A study of pavement noise for asphalt pavements with different service life in national highway," in Proceedings of the Inter-noise o Noise-Control Congress \& Conference, Melbourne, Australia, 2014.

[8] H. Zhang, Z. Wang, H. Cheng, and Y. Li, "Mechanism of pavement disease of highway-bridge transition sections between the portals of tunnels in cold and arid regions," Journal of Inner Mongolia University. Natural Science Edition, vol. 45, pp. 435-440, 2014.

[9] B. Zheng, S. Zhu, Y. Cheng, and X. Huang, "Analysis on influence factors of adhesion characteristic of tire-asphalt pavement based on tire hydroplaning model," Journal of Southeast University. Natural Science Edition, vol. 48, pp. 719-725, 2018.

[10] M. N. Alamdarlo and S. Hesami, "Measuring the effect of pavement porosity filling on skid resistance by numerical model and field test," Measurement, vol. 152, p. 107269, 2020.

[11] R. Kienle, W. Ressel, T. Götz, and M. Weise, "The influence of road surface texture on the skid resistance under wet conditions," Proceedings of the Institution of Mechanical Engineers, Part J: Journal of Engineering Tribology, vol. 234, no. 3, pp. 313-319, 2018.

[12] R. B. Kogbara, E. A. Masad, E. Kassem, A. Scarpas, and K. Anupam, "A state-of-the-art review of parameters influencing measurement and modeling of skid resistance of asphalt pavements," Construction and Building Materials, vol. 114, pp. 602-617, 2016.

[13] A. El-Desouky, "Investigating the effect of temperature variations on the measured airfield pavement skid resistance," Construction and Building Materials, vol. 161, pp. 649-653, 2018.

[14] G. Wang, G. Smith, and R. Shores, "Pavement noise investigation on North Carolina highways: an on-board sound intensity approach," Canadian Journal of Civil Engineering, vol. 39, no. 8, pp. 878-886, 2012.

[15] Q. C. Wei, X. F. Zhang, C. Z. Zang, and N. I. Yong-Jun, "Study on active noise control sound field in highway tunnel," China Journal of Highway \& Transport, vol. 30, no. 1, pp. 77-82, 2017.

[16] Z. Zhang, B. Luan, X. Liu, and M. Zhang, "Effects of surface texture on tire-pavement noise and skid resistance in long freeway tunnels: from field investigation to technical practice," Applied Acoustics, vol. 160, Article ID 107120, 2020.

[17] Z. H. Cong, S. Wang, N. X. Zheng, G. Q. Sun, and W. U. XiRong, "Asphalt mixture design with anti-skidding and low noise performance in tunnel pavement," China Journal of Highway \& Transport, vol. 25, pp. 36-41, 2012.

[18] People's Communications Publishing House, Technical Guidelines for Construction of Highway Cement Concrete Pavements, People's Communications Publishing House, Beijin, China, F30-2014, J.T., 2014.

[19] M. Buret, J. Mcintosh, and C. Simpson, "Long-term asphalt trial: results of acoustic tests after three years," Acoustics Australia, vol. 44, no. 2, pp. 273-281, 2016.

[20] M. Sakhaeifar, A. Banihashemrad, G. Liao, and B. Waller, "Tyre-pavement interaction noise levels related to pavement surface characteristics," Road Materials \& Pavement Design, vol. 19, no. 5, pp. 1-13, 2017.

[21] M. E. Nilsson, "A-weighted sound pressure level as an indicator of short-term loudness or annoyance of road-traffic sound," Journal of Sound and Vibration, vol. 302, no. 1-2, pp. 197-207, 2007.

[22] Q.-Y. Tang and C.-X. Zhang, "Data processing system (DPS) software with experimental design, statistical analysis and data mining developed for use in entomological research," Insect Science, vol. 20, no. 2, pp. 254-260, 2013.

[23] Q. Y. Tang, DPS Data Processing System-Experimental Design, Statistic Analysis and Data Mining, Science Press, Beiing, China, 2010.

[24] L. Hu, D. Yun, J. Gao, and C. Tang, "Monitoring and optimizing the surface roughness of high friction exposed aggregate cement concrete in exposure process," Construction and Building Materials, vol. 230, Article ID 117005, 2020. 